\title{
Abordagem das propriedades coligativas das soluções numa perspectiva de ensino por situação- problema
}

Valéria Barboza Veríssimo

Angela Fernandes Campos

\begin{abstract}
Resumo
Nesse estudo buscou-se identificar e avaliar as ações de aprendizagem dos estudantes e as atitudes deles durante o processo de resolução de uma situaçãoproblema (SP) relacionada com alguns aspectos das propriedades coligativas das soluções. A metodologia considerou as orientações de Meirieu para construção de uma situação-problema (SP) e contemplou os procedimentos: elaboração da SP; elaboração de um questionário de concepções prévias e de um texto intitulado "Água: soluções e propriedades"; elaboração de atividades experimentais; e análise das respostas dos estudantes à situação-problema. Os resultados obtidos mostraram que a estratégia didática pautada na resolução da SP exigiu dos estudantes a superação dos conflitos cognitivos gerados, o texto trabalhado potencializou as argumentações e contra-argumentações dos estudantes durante as discussões sobre os resultados das atividades experimentais, e as atividades experimentais favoreceram 0 desenvolvimento de competências sociais, procedimentais e comunicativas pelos estudantes, estimulando-os a superar dificuldades específicas do domínio científico e a resolução da SP.
\end{abstract}

Palavras-chave: Ensino de Química, situação-problema, propriedades coligativas das soluções.

\footnotetext{
Abstract

Addressing the colligative properties of solutions from the perspective of teaching by problem-situation

This study identified and evaluated the actions of student learning and their attitudes during the process of solving a problem situation (PS) related to some aspects of the colligative properties of solutions. The methodology considered Meirieu's orientations for construction of a problem situation (PS) and included: preparation of the PS, development of a questionnaire of previous conceptions, a text entitled "Water: solutions and properties", development of experiments, and
} 
analysis of students' responses to the problem situation. The results showed that the teaching strategy based on resolution of SP required to overcome the students' cognitive conflicts, the text potentiated the arguments and counterarguments of the students during discussions on the experiment results, and experimental activities favored the development of social skills, procedural and communication by students, encouraging them to overcome specific difficulties of the scientific domain and the resolution of PS.

Keywords: Chemistry teaching, problem-situation, colligative properties of solutions.

\section{Introdução}

$\mathrm{Na}$ literatura em Educação em Ciências, encontramos diversos trabalhos que apresentam propostas para o ensino com base em situação-problema (SP) (Meirieu, 1998; Pozo, 1998; Cachapuz, 1999; Perrenoud, 1999; Macedo, 2002). Estas pesquisas apontam a utilização de situações-problema como ponto de partida para aprendizagens promotoras do conhecimento escolar. Trata-se de ir ao encontro de objetivos educacionais no sentido do desenvolvimento pessoal e social dos alunos, em que os conteúdos e processos deixem de ser fins para ser meios de encontrar respostas possíveis sobre questões que ganharam sentido. Sob essa perspectiva, o desafio da escola e dos professores é o de garantir a superação de um modelo tradicional de ensino, em que os alunos absorvem enormes quantidades de informações, com o propósito de que sejam memorizadas e devolvidas nas avaliações da mesma forma que foram transmitidas pelo professor (Schnetzler, 2004). Isso significa que o professor deverá procurar meios para encaminhar a aprendizagem utilizando uma abordagem não "mecanicista", ou seja, aquela que busca a resposta esperada e/ou segue apenas caminhos anteriormente por ele direcionados, mas principalmente, elaborando atividades com procedimentos que sejam capazes de estimular os estudantes na realização das tarefas e instigar a curiosidade dos mesmos, orientando-os na compreensão do conhecimento científico, principalmente para inseri-los de forma ajustada na sociedade (Insausti, 1997). Nesse sentido, o ensino por SP pode contribuir.

Segundo Meirieu (1998, p.112), situação-problema (SP) é "uma situação didática na qual, se propõe ao sujeito uma tarefa que ele não pode realizar sem efetuar uma aprendizagem precisa. Esta aprendizagem que consiste o verdadeiro objetivo da situação-problema se dá ao vencer um obstáculo na realização da tarefa". É importante ressaltar que a SP deve estar ajustada ao nível e possibilidade dos estudantes, ou seja, não deve ser tão fácil pois a resolução ocorrerá de forma imediata, nem ser tão difícil contribuindo para que os estudantes evitem o processo de resolução que demandará reflexão, ações e tomada de decisões. Além disso, a SP deverá despertar o interesse (motivação) pela aprendizagem. 


\section{Situação-Problema e a Experimentação}

As atividades experimentais introduzidas nos currículos escolares de Ciências da Natureza são utilizadas como estratégias de ensino há mais de três décadas (Goi; Santos, 2008). Em trabalhos desenvolvidos nas décadas 70 e 80 , professores questionavam sobre a efetividade dos trabalhos experimentais (Hofsttein; Luneta, 1982) e apontavam falhas de nível metodológico na abordagem experimental, por ser utilizada apenas como ilustração para validação do conhecimento teórico e por restringir a participação dos estudantes a meros reprodutores do conhecimento científico, ou seja, observadores de atividades experimentais para a validação deturpada do conhecimento científico (Zuliani; Ângelo, 2001).

Para promover e efetivar o trabalho experimental surgem as experimentações "livres" que não consideram o papel importante das construções das hipóteses e a coerência do conhecimento a ser construído durante o desenvolvimento dos trabalhos experimentais (Gil Pérez, 1996). Isso significa dizer que, os estudantes desenvolvem o trabalho experimental e, ao mesmo tempo, desconhecem o objeto de estudo desse trabalho, isto é, a experimentação é utilizada com o intuito de validar a reprodução dos conhecimentos científicos trabalhados.

Segundo Insausti (1997) é de suma importância o professor planejar estratégias didáticas que possibilitem trabalhar o desenvolvimento das habilidades dos estudantes, no que se refere ao fato de auxiliá-los a relacionar os conceitos trabalhados pelo professor aos fenômenos observados no laboratório. Em concordância com essa posição, ressaltamos a importância do professor planejar as atividades experimentais oportunizando aos educandos as condições necessárias de aprendizagem para o entendimento do conhecimento científico, não no intuito de responder o "por que desenvolver a atividade científica" e sim perguntar "para quê" desenvolvêla. Logo, acreditamos que cada estudante necessita do conhecimento científico não apenas para consolidar uma educação formal, mas principalmente para inseri-lo de forma ajustada para desenvolver o papel de cidadão na sociedade.

Segundo Francisco Jr (2008), uma das funções da experimentação é mediatizar os educandos e o objeto cognoscitivo. Do nosso ponto de vista, o professor ao desenvolver atividades de caráter investigativo precisa aproximar o educando com o objeto de conhecimento sem seguir procedimentos repetitivos, e sim atividades problematizadoras que possibilitem ao educando questionar os fenômenos e buscar respostas para seus questionamentos. Com isto, salientamos a necessidade do professor oportunizar aos estudantes atividades experimentais de cunho investigativo e, ao mesmo tempo, utilizar materiais concretos que poderão contribuir para instigar a curiosidade do estudante e ao mesmo tempo auxiliá-lo no processo de resolução da situação-problema. Vale ressaltar que esse processo exigirá dos estudantes competências de 
ordens sociais, processuais e comunicativas necessárias para o desenvolvimento do conhecimento científico (Martins et al., 2004).

De acordo com Silva e Núnez (2002, p.4), "os conceitos se ressignificam no próprio trabalho de solução de problemas por meio da prática experimental no laboratório". Logo, o professor, ao planejar as suas estratégias de ensino, estará atuando como mediador no processo ensino e aprendizagem. Assim, o professor ao mediatizar as atividades que os estudantes realizam, dentre elas, as atividades experimentais, deverá instigar a curiosidade dos mesmos na busca de respostas para situação-problema proposta (Meirieu, 1998). Sob essa perspectiva, selecionamos o conteúdo químico propriedades coligativas das soluções para abordá-lo em sala de aula numa perspectiva de ensino por situação-problema utilizando alguns instrumentos didáticos, dentre eles, atividades experimentais como etapa fundamental na intervenção didática. O referido conteúdo foi escolhido a partir da constatação em nossa prática docente: i) da dificuldade apresentada pela maioria dos estudantes do ensino médio em compreender o assunto de propriedades coligativas; ii) do fato que este conteúdo químico está relacionado com vários fenômenos do dia-a-dia dos estudantes como, por exemplo, o fenômeno da osmose responsável pela ascensão da seiva nas plantas, as técnicas de conservação dos alimentos, técnicas utilizadas na produção de cosméticos que resistem a temperaturas muito baixas e uso de aditivos químicos para modificar a temperatura de congelamento e ebulição de um solvente; e iii) por envolver diversos conceitos químicos importantes, como, por exemplo, substância simples e composta, soluções, ponto de fusão, ponto de ebulição, pressão de vapor, osmose, natureza química das substâncias e as forças de interações intermoleculares que podem emergir nas discussões realizadas durante as atividades experimentais e resolução da SP. Dessa forma, o objetivo desse estudo compreende identificar as ações de aprendizagem dos estudantes (competências sociais, procedimentais e comunicativas) e as atitudes deles em seus grupos após a vivência de uma metodologia de ensino pautada na resolução de uma SP.

\section{Metodologia}

Este estudo é parte de uma pesquisa mais ampla desenvolvida em uma dissertação de mestrado que investigou o uso de uma situação-problema como estratégia didática para o ensino do conteúdo propriedades coligativas das soluções. A pesquisa foi realizada em uma escola da rede pública estadual, localizada no bairro de Santo Amaro na cidade do Recife/PE e desenvolvida com uma turma da 2a série do ensino médio formada por 12 (doze) estudantes. Desse total, sete estudantes divididos em um grupo com três componentes (G1) e dois grupos com 2 componentes (grupos G2 e G3), participaram de todos os momentos da pesquisa. 
De um modo geral, os procedimentos metodológicos da pesquisa contemplaram:

1) elaboração de uma SP tomando como referencial teórico as orientações propostas por Meirieu (1998) (quadro 1), que os professores devem levar em consideração no processo de construção de uma SP. Nesse sentido, A SP foi elaborada e apresentada aos estudantes como segue:

"É comum em países muito frios que as pessoas coloquem sal para ajudar a derreter a neve e impedir que se forme novamente nas estradas, a fim de que se evitem acidentes. Outro fenômeno interessante que acontece é quando adicionamos uma porção de sal em água fervendo, pois a mesma pára de ferver, precisando ser mais aquecida para que volte à fervura. Utiliza-se também o sal para desidratar e conservar os alimentos. Como esses fatos podem ser explicados utilizando os aspectos representacional, macroscópico e microscópico do conhecimento químico?"

\begin{tabular}{|c|c|}
\hline Orientações de Meirieu (1998), p.181. & Relações com a SP proposta \\
\hline $\begin{array}{l}\text { i- Qual é o meu objetivo? O que eu quero fazer } \\
\text { com que o aluno adquira e que para ele } \\
\text { represente um patamar de progresso } \\
\text { importante? }\end{array}$ & $\begin{array}{l}\text { Promover aprendizagem em relação aos } \\
\text { conceitos científicos envolvidos no conteúdo } \\
\text { das propriedades coligativas das soluções, bem } \\
\text { como o desenvolvimento de procedimentos e } \\
\text { atitudes nos estudantes. }\end{array}$ \\
\hline $\begin{array}{l}\text { ii -Que tarefa posso propor que requeira, para } \\
\text { ser realizada, o acesso a esse objetivo? }\end{array}$ & $\begin{array}{l}\text { Leitura e discussão de um texto; seis atividades } \\
\text { experimentais para abordagem das } \\
\text { propriedades físicas das soluções e } \\
\text { comparação com as propriedades físicas do } \\
\text { solvente puro. }\end{array}$ \\
\hline $\begin{array}{l}\text { iii - Que dispositivo devo instalar para que a } \\
\text { atividade mental permita, na realização da } \\
\text { tarefa, o acesso ao objetivo? } \\
\text { a) Que materiais, documentos, instrumentos } \\
\text { devo reunir? } \\
\text { b) Que instruções-alvo devo dar para que os } \\
\text { alunos tratem os materiais para cumprir a } \\
\text { tarefa? }\end{array}$ & $\begin{array}{l}\text { a) Foi trabalhado um texto temático sobre a } \\
\text { água: soluções e propriedades, um } \\
\text { questionário sobre os conceitos envolvidos na } \\
\text { temática, modelos moleculares, consultas em } \\
\text { tabelas, além de momentos reservados para a } \\
\text { socialização do conhecimento através de } \\
\text { debates e intervenção } \\
\text { professora/pesquisadora. } \\
\text { b) Os estudantes foram instruídos a trabalhar } \\
\text { em grupos, sempre discutindo suas idéias e as } \\
\text { confrontando com a idéia do outro, para se } \\
\text { chegar a um consenso respeitando as idéias } \\
\text { dos seus pares. }\end{array}$ \\
\hline $\begin{array}{l}\text { iv- Que exigências devem ser introduzidas para } \\
\text { impedir que os sujeitos evitem a aprendizagem? }\end{array}$ & $\begin{array}{l}\text { Os estudantes foram estimulados a participar } \\
\text { de todas as etapas da pesquisa. Procurou-se } \\
\text { instigar a curiosidade deles a fim de que os } \\
\text { mesmos encontrassem resposta(s) à SP. }\end{array}$ \\
\hline
\end{tabular}


v - Que atividades posso propor que permitam negociar o dispositivo segundo diversas estratégias? Como variar os instrumentos, procedimentos, níveis de orientação, modalidades de reagrupamento?
A primeira atividade foi a leitura do texto temático com informações gerais sobre os conceitos envolvidos no estudo das propriedades coligativas das soluções e fenômenos do seu dia-a-dia. A segunda atividade envolveu a manipulação de estruturas moleculares para compreensão da estrutura química das moléculas do solvente da atividade experimental, justificando a volatilização das substâncias (água destilada, álcool e propanona)

Quadro 1. Questões que o professor deve levar em consideração no processo de elaboração de uma situação-problema, segundo Merieu (1998).

Para a resolução da SP proposta foram desenvolvidas atividades com os alunos considerando os três níveis do conhecimento químico, fenomenológico, tópicos do conhecimento passiveis de visualização concreta, bem como de análise ou determinação das propriedades dos materiais e de suas transformações; teórico, onde se encontram informações de natureza atômico-molecular, envolvendo, portanto, explicações baseadas em termos abstratos como átomo, molécula, íon, elétron; e representacional, envolvem os conteúdos químicos de natureza simbólica, que compreende informações inerentes à linguagem química, como fórmulas $e$ equações químicas (Machado, 1999, p. 163).

2) elaboração de um questionário para levantamento das concepções prévias dos estudantes sobre o conteúdo propriedades coligativas das soluções e suas relações com fenômenos do dia-a-dia: i) Quanto ao consumo humano, por que não podemos beber a água do mar? ii) Será que acontece alguma mudança nas propriedades físicas da água quando a mesma encontra-se em solução? Comente. iii) A presença dos sais minerais pode modificar alguma propriedade física da água, tais como: ponto de ebulição, ponto de fusão e volatilização? Justifique sua resposta. iv) O que são forças de interações intermoleculares? v) Os médicos recomendam uma solução de $0,9 \%$ de $\mathrm{NaCl}$ para reidratação oral ou venosa. Será que poderíamos mudar a concentração do soro? Justifique sua resposta. O questionário foi elaborado e aplicado para que a professora/pesquisadora pudesse avaliar se a SP proposta era adequada às possibilidades cognitivas dos estudantes além de buscar identificar se os alunos apresentavam conhecimentos prévios relevantes em relação ao conteúdo abordado;

3) elaboração de um texto didático intitulado "Água: soluções e propriedades". Esse texto foi construído com base no livro de Santos et al., (2005). Esse livro foi escolhido, pois tem uma proposta de abordar conteúdos a partir de temáticas da sociedade. A elaboração do texto teve 
como finalidade contextualizar algumas informações tecnológicas utilizadas na indústria química acerca da água: propriedades e soluções, envolvendo situações do dia-a-dia dos estudantes sobre o conteúdo de propriedades coligativas das soluções e, ao término da sua leitura, promover um debate com a participação dos estudantes e da professora/pesquisadora. Segundo Moraes et al (2004), é de suma importância, para o processo ensino e aprendizagem, o professor, ao planejar suas ações metodológicas, utilizar um texto para auxiliar a compreensão do conteúdo pelo educando. Além disso, Zanon e Freitas (2007) ressaltam que se o texto está relacionado com situações do dia-a-dia dos estudantes potencializará as argumentações na sala de aula.

4) elaboração de atividades experimentais e análise da atividade experimental 4;

5) análise das respostas dos estudantes à SP.

A intervenção didática foi realizada em dois momentos. O primeiro momento, realizado na escola citada, teve duração de 100 minutos correspondentes a duas aulas de 50 minutos cada e contemplou as seguintes atividades: 1) aplicação do questionário aos estudantes; 2) leitura e discussão do texto com o grande grupo; 3) apresentação da situação-problema pela professora/pesquisadora.

O segundo momento, realizado no laboratório do Departamento de Química da Universidade Federal Rural de Pernambuco (UFRPE), teve duração de 480 minutos com 80 minutos de intervalo correspondentes a oito aulas de 50 minutos cada e contemplou o desenvolvimento de seis atividades experimentais, a saber: a) Atividade experimental 1 Testando a natureza química do soluto não volátil nas soluções eletrolíticas e não - eletrolíticas; b) Atividade experimental 2 - Investigando a influência das forças intermoleculares na volatilização do solvente; c) Atividade experimental 3 - Investigando a influência da concentração do soluto não volátil nos valores da pressão de vapor do solvente; d) Atividade experimental 4 Investigando a influência da adição do soluto não volátil na temperatura de ebulição das soluções; e) Atividade experimental 5 - Investigando a influência da adição de um soluto não volátil nos valores da temperatura de congelamento das soluções; f) Atividade experimental 6 - Investigando a influência da concentração do soluto não volátil no fenômeno da osmose.

Cada atividade experimental foi desenvolvida obedecendo as seguintes etapas: 1) leitura e explicação dos procedimentos metodológicos da atividade experimental pela professora/pesquisadora; 2) realização da atividade experimental pelos grupos (G1, G2, G3); 3) discussão dos estudantes em seus grupos sobre questões propostas na atividade experimental que envolviam situações do dia-a-dia; e 4) discussão com o grande grupo com ênfase nos aspectos representacional, microscópico e macroscópico do conteúdo abordado.

Discutiremos neste artigo a análise das respostas dos estudantes ao questionário de concepções prévias, discussão do texto e uma das seis atividades experimentais, enquanto instrumentos didáticos da intervenção aplicada, buscando identificar e avaliar as ações de 
aprendizagem dos estudantes (competências sociais, procedimentais e comunicativas) e as atitudes dos grupos no processo de resolução da SP proposta.

\section{Resultados e Discussão}

\section{Análise do Questionário de Concepções Prévias}

A análise do questionário de concepções prévias mostrou que na questão i) a maioria dos estudantes respondeu: "Porque a água do mar tem uma grande concentração de sal"; "A quantidade de sal é muito grande o que prejudica a saúde". Nenhuma das respostas fez menção

ao desequilíbrio osmótico no organismo provocado pelo excesso de sal, sendo as respostas caracterizadas como do senso comum.

Com relação à questão ii) a maioria dos estudantes respondeu que "sim" mas nenhum deles especificou as mudanças nas propriedades físicas do solvente provocadas pela presença do soluto não volátil. A visão microscópica do conhecimento químico não foi utilizada para especificar a composição química da água pura ou das espécies químicas na solução.

Quanto à questão 3 nenhum estudante conseguiu responder de forma satisfatória, apesar da maioria ter respondido "sim". Além disso, algumas respostas revelaram erros conceituais quanto à natureza química dos sais minerais: "Sim. Os sais são moléculas que se modificam ao contato de alguma propriedade física". Na verdade, os sais não são moléculas e não se modificam no contato. A presença dos saís minerais entre as moléculas do solvente modificam as propriedades físicas do solvente na solução devido às interações atrativas estabelecidas.

Na questão 4 apenas dois alunos conseguiram responder satisfatoriamente: "São forças de interação positivas e negativas de uma solução".

Na questão 5 a maioria dos estudantes apresentou respostas baseadas no senso comum: "não, se mudar a concentração iria ter algumas complicações"; "não, por que já tem a medida certa". Nenhuma resposta fez menção ao fenômeno de osmose.

Os resultados obtidos do questionário sugerem a ausência de conhecimentos prévios relevantes dos estudantes referentes aos aspectos coligativos das soluções. Nesse sentido, a abordagem desse conteúdo em sala de aula por meio da SP proposta pode contribuir. 


\section{Apresentação da situação-problema, leitura e discussão do texto - Água: soluções e propriedades.}

A SP foi lida e distribuída aos estudantes que logo em seguida comentaram:

"Professora a gente não sabe responder"

Então a professora/pesquisadora indagou:

"Gente, primeiramente vocês devem buscar a compreensão do problema".

Logo, uma estudante comentou:

“Eu mesma já li duas vezes e não entendi!”

E a professora/pesquisadora respondeu:

A compreensão da situação-problema necessita de reflexão e a resolução deverá ser orientada por "tarefas" onde vocês devem buscar as novas informações que deverão auxiliá-los a encontrar a resposta".

Logo após a justificativa, um estudante ficou curioso e perguntou:

"Mas, professora que tarefas são essas?"

E a mesma respondeu:

"Será uma das etapas da pesquisa para tentarmos responder S SP, nela constam seis atividades experimentais investigativas a serem desenvolvidas no laboratório de Química da UFRPE."

Então, disseram:

"Vai ser legal professora!"

"Só assim, a gente vai puder conhecer o laboratório de Química da Universidade!"

Esse diálogo foi muito proveitoso, pois, possibilitou a professora/pesquisadora avaliar a aceitação dos estudantes e o interesse em participar do trabalho de pesquisa. Os educandos se mantiveram participativos e abertos ao diálogo de forma solidária, respeitosa e com liberdade de expressão. Assim, na apresentação da SP com a explicitação das expectativas dos estudantes, possibilitou-se o estabelecimento de um contrato de trabalho do grupo, visando acordar os critérios que nortearam a participação dos grupos no processo de resolução da SP. Além disso, durante a apresentação da SP percebemos que conflitos cognitivos foram gerados nos estudantes e a motivação (MEIRIEU, 1998) para buscar resposta(as) à SP proposta, como esperado.

Em seguida, o texto foi lido pelos estudantes e a professora/pesquisadora discutiu com eles sobre a natureza química da água e do sal; as forças de interação soluto-solvente na solução; a 
osmose e desidratação dos alimentos e as propriedades físicas como, ponto de fusão e ebulição de substâncias e misturas.

\section{Análise da Atividade Experimental: Investigando a influência da adição do Soluto não volátil na temperatura de ebulição das soluções.}

A escolha para análise nesse momento da atividade experimental - Investigando a influência da adição do Soluto não volátil na temperatura de ebulição das soluções - justifica-se por sua relevância em subsidiar informações importantes que auxiliaram o entendimento dos estudantes acerca de temáticas que envolviam situações do dia-a-dia. Inicialmente, nossas discussões referem-se às ações e atitudes dos participantes (professora/pesquisadora e estudantes) da atividade experimental e aos conceitos formalizados em diferentes momentos da atividade experimental analisada. Esses diferentes momentos correspondem ao início (primeiro momento), desenvolvimento (segundo momento) e conclusão (terceiro momento) da respectiva atividade experimental. Em seguida, apresentamos um quadro-síntese representativo da análise realizada.

No início, foi realizada uma leitura dos procedimentos da atividade experimental. A professora/pesquisadora solicitou que os estudantes testassem o aquecimento da chapa e observassem a numeração dos quatro sistemas (sistema I: água destilada; sistema II: solução aquosa de sacarose $0,3 \mathrm{~mol} / \mathrm{L}$; sistema III: solução aquosa de cloreto de sódio $0,3 \mathrm{~mol} / \mathrm{L}$; sistema IV: solução aquosa de cloreto de sódio $1 \mathrm{~mol} / \mathrm{L}$ ).

Neste momento, as ações de aprendizagem desenvolvidas pelos estudantes foram: a) obter dados; b) interpretar esses dados com explicações científicas; e c) registrar a leitura do tempo de aquecimento com uso do cronômetro e a leitura da temperatura com uso do termômetro.

Quanto às atitudes dos grupos, identificamos que eles, inicialmente, executaram a atividade experimental, em seguida, permaneceram atentos aos procedimentos solicitados para sua realização. Entretanto, levaram algum tempo para aquecer a chapa e distribuir os sistemas I, II, III e IV. No segundo momento, a professora/pesquisadora convidou cada grupo para apresentar as respostas para a questão proposta na ficha-tarefa: como você justifica o volume evaporado em cada sistema? A título de exemplificação, apresentamos a resposta satisfatória do grupo G3 para a questão proposta: "O volume evaporado do sistema I (água) > II (sacarose 0,3 mol) > III ( $\mathrm{NaCl}$ 0,3 $\mathrm{mol})>\mathrm{IV}(\mathrm{NaCl} 1 \mathrm{~mol} / \mathrm{L})$ por que o sal impede a saída do vapor da água". O grupo ao comparar o volume evaporado de cada sistema utilizou uma linguagem científica aceitável e explicou os fatos em nível microscópico. Além disso, comentou sobre os tipos de força que atuam em cada sistema 
(I e II, pontes de hidrogênio, III e IV, íon-dipolo) utilizando os modelos geométricos (Atomlig educação 77).

Neste momento, as ações de aprendizagem desenvolvidas pelos estudantes foram: a) responder a questão da ficha-tarefa; b) compreender e utilizar a linguagem científica; e c) argumentar sobre as informações observadas durante o experimento.

Quanto às atitudes dos grupos, observamos que durante a atividade experimental eles permaneceram atentos aos procedimentos, engajados na execução da mesma e na apresentação das respostas para as questões propostas na ficha-tarefa.

Vale ressaltar que tais discussões nesse momento foram muito proveitosas. Por exemplo, um membro do grupo G1 comentou sobre a escassez da água potável e disse: "Professora, agora eu sei por que a água potável do planeta está se acabando". A professora falou: "Você sabe o motivo? Ele respondeu: "Deve ser por que a água potável evapora mais facilmente". A professora aproveitou o momento e explicou que outros fatores de ordem socioeconômicas e ambientais contribuem para a escassez da água potável no mundo como, por exemplo, o desperdício, as mudanças climáticas, a falta de saneamento básico, e a poluição ocasionada pelas indústrias, dentre outros.

Neste momento, um dos aspectos relevantes observados, foi a contribuição do texto (instrumento didático utilizado em momento anterior ao desenvolvimento das atividades experimentais) lido pelos estudantes. Ao nosso ver, quando o estudante (membro do grupo G1) fez a colocação anterior, mostrou indícios de que o texto o auxiliou a estabelecer relações entre os conceitos científicos discutidos e os fenômenos observados durante a atividade experimental e a refletir sobre problemas do dia-a-dia em busca da compreensão dos fatos.

Posteriormente (terceiro momento), a professora/pesquisadora fez uma intervenção para formalizar os conceitos científicos trabalhados no experimento, a saber: forças de interações intermoleculares; distinção entre substância e mistura; temperatura de ebulição; concentração em $\mathrm{mol} / \mathrm{L}$ e pressão de vapor.

Neste momento, as ações de aprendizagem desenvolvidas pelos estudantes foram: a) argumentar sobre as questões propostas; e b) associar as informações científicas aos efeitos coligativos observados na atividade experimental.

Quanto às atitudes dos grupos, observamos que neste momento, eles permaneceram atentos a formalização dos conceitos científicos pela professora/pesquisadora e aos registros dos mesmos e questionaram sobre situações do dia-a-dia abordadas no texto lido anteriormente.

Além disso, a atividade experimental despertou a curiosidade dos estudantes para problemas como a escassez da água potável. Como podemos mostrar na fala de um dos membros do grupo G1: "A água do mar evapora menos e, a água potável evapora mais, isto por que ela 
contém menor quantidade de sais minerais então, apresenta maior pressão de vapor e menor temperatura quando ferver".

De um modo geral, a atividade experimental 4 exigiu a compreensão de conceitos em nível microscópico para explicar o calor recebido durante o aquecimento das soluções, o que pode justificar o fato dos estudantes comentarem que, apesar de terem conseguido realizar a atividade experimental, tiveram dificuldade para abstrair as informações científicas a partir das observações sobre o experimento.

Após o terceiro momento, a professora/pesquisadora voltou a comentar sobre os fenômenos do dia-a-dia abordados no texto Água: soluções e propriedades e explicou tais fenômenos utilizando os três níveis do conhecimento químico: macroscópico, microscópico e representacional. A seguir, apresentamos uma síntese da análise dos três momentos da atividade experimental 4 (quadro 2 ). 


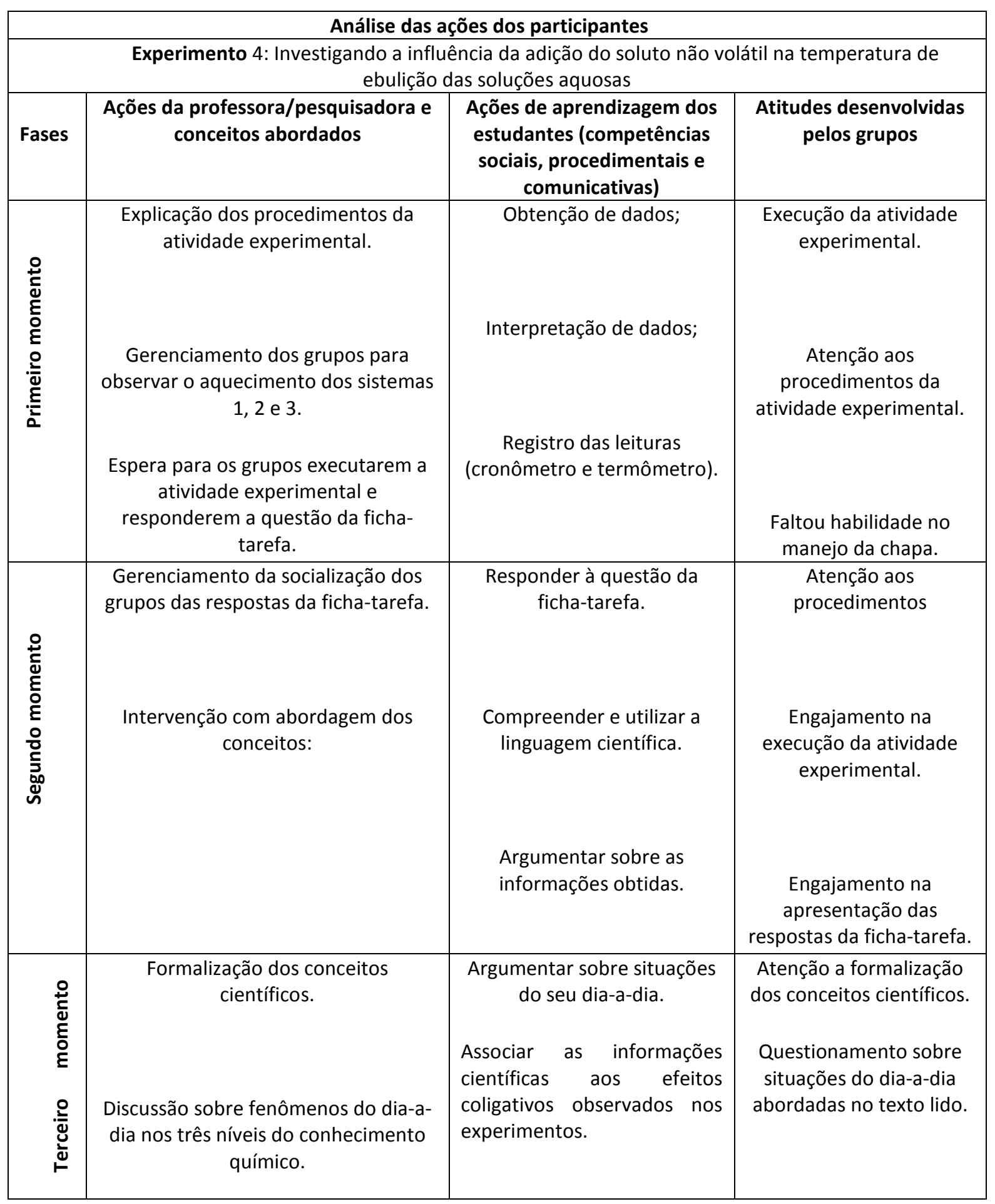

Quadro 2. Síntese da análise das ações dos participantes: Atividade Experimental 4.

Fizemos esse procedimento de análise para as seis atividades experimentais, e pudemos concluir que todas, considerando suas especificidades e objetivos, favoreceram, enquanto instrumentos didáticos de uma intervenção didática pautada na resolução de uma $\mathrm{SP}$, o R. B. E. C. T., vol 4, núm 3, set./dez. $2011 \quad$ ISSN - 1982-873X 
desenvolvimento de ações de aprendizagem (competências sociais (cooperar em equipe, recolher dados, executar procedimentos, ou interpretar, em termos gerais, informação científica), procedimentais (capacidade para observar, experimentar, avaliar, interpretar gráficos, mobilizar) e competências comunicativas (capacidade para usar e compreender linguagem científica, registrar, ler e argumentar usando informação científica) pelos estudantes, estimulando-os a superar dificuldades tais como: capacidade para observar, registrar, argumentar, e avaliar os resultados das respectivas atividades. Essas competências são específicas do domínio científico, e ao nosso ver, auxiliaram os estudantes na construção do conhecimento científico (Martins et al., 2004) envolvido com as propriedades coligativas das soluções.

Apesar de não ter sido tarefa simples, o desenvolvimento das atividades experimentais permitiu que os estudantes, ao participarem efetivamente da execução dos experimentos, demonstrassem ações de aprendizagem (competências) e, também desenvolvessem as operações mentais para responder a SP. Aspecto este que abordaremos em artigo posterior.

Além disso, pudemos observar que quando as atividades experimentais são trabalhadas articuladas às questões do dia-a-dia, como, por exemplo, o equilíbrio das chuvas, o problema das calotas de gelo, etc., elas podem contribuir também para o desenvolvimento de procedimentos atitudinais favorecendo, dentre outros aspectos, a formação de um educando mais autônomo (BRASIL, 1999). Assim, a forma como as atividades experimentais foram trabalhadas pela professora/pesquisadora tornou o conteúdo de propriedades coligativas das soluções mais atrativo para os estudantes, pois enfatizou-se os processos físico-químicos necessários ao entendimento das questões do dia-a-dia anteriormente citadas. (Almeida; Quadros, 2008).

\section{Análise das repostas dos estudantes à situação-problema proposta.}

De uma maneira geral, os grupos não demonstraram dificuldades em organizar as ideias, principalmente na escrita do texto, porém, em relação à questão conceitual, o termo "partícula do soluto" e a unidade semântica "molécula da água" não foram bem empregados, em alguns momentos, por todos (visão microscópica). No entanto, a partir das atividades desenvolvidas, os estudantes tiveram a oportunidade de observar os fatos concretos, o que auxiliou na compreensão das interações soluto-solvente e as modificações no comportamento do solvente na solução, frente ao aquecimento, congelamento, à quantidade de vapor do solvente produzido e osmose nos meios (hipotônico, hipertônico e isotônico) (Fonseca, 2001). Desta forma, foi necessário, portanto, transitar entre os três níveis do conhecimento químico igualmente para que 
possibilitassem aos estudantes a compreensão da situação-problema a partir da dialética entre teoria e experimento, pensamento e fatos concretos (Mortimer et al., 2000). Logo, consideramos que houve interesse e participação de todos em busca de aprender durante a resolução da situação-problema. Os desafios estiveram ao nível cognitivo dos estudantes, porém não de forma direta. Os mesmos, para encontrarem a resposta para situação-problema, tiveram que refletir, rever seus conceitos frente às dificuldades (desafios) (Meirieu, 1998). Desta maneira, percebemos que os estudantes não se mostraram presos apenas ao conhecimento do dia-a-dia, mas, também conseguiram interligar os conceitos químicos trabalhados, criando estratégias adequadas e necessárias para encontrar uma solução para a SP. A seguir, a resposta de um dos grupos, G3, à SP proposta:

"1 - A temperatura de congelamento baixa, causando o que chamamos de crioscopia. Quando adicionado o sal na neve, a neve dissolve e fica mais difícil de voltar o seu congelamento.

2 - A água para de ferver quando adicionamos sal, porque o soluto reúne partículas de água e, quando volta a ferver, a volatilização fica maior (Figura 1)

3 - Quando adicionamos sal ou açúcar acontece a desidratação, envolvendo o fenômeno da osmose, porque, a medida que é adicionado o sal, maior o tempo de conservação da carne."

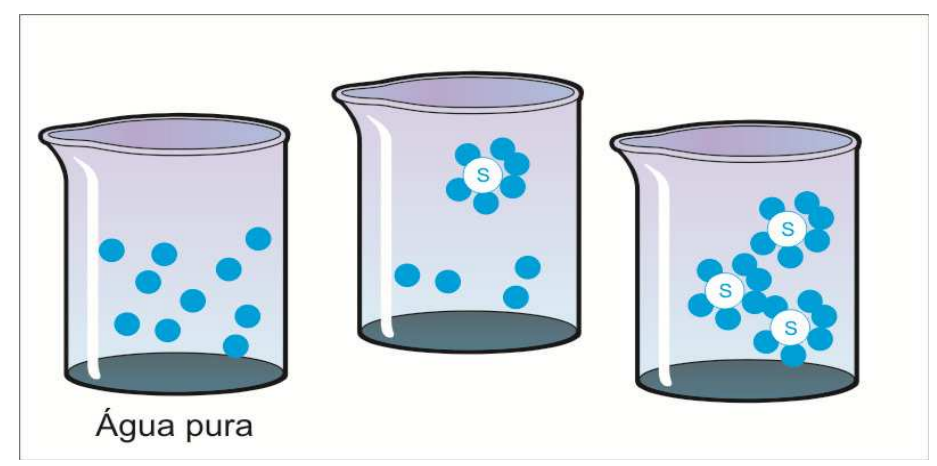

Figura 1. Representação microscópica da interação entre moléculas do solvente (água) e entre soluto-solvente construída pelo grupo $G 3$.

\section{Considerações Finais}

De um modo geral, a estratégia didática pautada na resolução da SP se mostrou bastante eficaz. Durante o seu desenvolvimento, foi exigido determinado nível de compreensão que provocou conflitos nos estudantes. Por conseguinte, eles buscavam continuamente superar

tais conflitos tomando por base as informações obtidas das observações durante as atividades experimentais. 
Dentre os instrumentos didáticos utilizados na intervenção didática, ressaltamos que o texto abordando a temática Água: soluções e propriedades possibilitou uma discussão ampla sobre problemas socioambientais e tecnológicos com ricas informações sobre os conceitos que envolvem o conteúdo de propriedades coligativas, os quais nortearam a compreensão da SP pelos estudantes.

Dessa forma, tanto a estratégia didática de resolução da SP como a temática abordada no texto, contribuíram para inserir os estudantes em atividades experimentais investigativas, pois propiciaram uma participação ativa dos mesmos com oportunidades de levantamento de hipóteses e questionamentos em direção a resolução da situação-problema.

As atividades experimentais foram determinantes para a resolução da SP pelos estudantes. Nessas atividades, eles tiveram a oportunidade de trabalhar com material didático manipulável, o que ao nosso ver, facilitou o desenvolvimento de ações de aprendizagem, tais como: interpretar dados, usar a linguagem científica, argumentar sobre as informações obtidas, etc., além de favorecerem o desenvolvimento de procedimentos atitudinais que parecem ter contribuído para uma formação mais autônoma. A forma como foram conduzidas oportunizou aos estudantes estabelecerem relações entre os conceitos científicos abordados no conteúdo das propriedades coligativas das soluções e os aspectos observados nos fenômenos, como pudemos verificar nas respostas dos grupos a SP.

Enfim, vivenciar uma intervenção didática pautada na resolução de uma SP sugere ao professor repensar o seu papel no processo de ensino e aprendizagem, o qual não deveria ser o de transmissor de ideias e informações, mas, o de facilitador na construção do conhecimento pelos estudantes. Nesse sentido, caberia ao professor optar por uma prática que viabilize a flexibilidade das ações pedagógicas e que possibilite trabalhar questões conceituais numa perspectiva investigativa e, dessa forma, ser um professor/pesquisador reflexivo da sua própria prática.

\section{Referências}

Almeida, J. A.; Quadros, A. L. Produzindo Aprendizagem em Química: Será isso Possível? In:

ENCONTRO NACIONAL DE ENSINO DE QUÍMICA, 2008, Curitiba. XIV ENEQ. Curitiba, 2008.

Brasil. Ministério da Educação. Secretaria de Educação Média e Tecnológica. Parâmetros

Curriculares Nacionais para o Ensino Médio. Brasília: MEC/Semtec, 1999. 
Cachapuz, A.; Praia, J; Jorge, M. Reflexões em torno da perspectiva do ensino das ciências; contributos para uma nova orientação curricular; ensino por pesquisa, Revista de Educação, V, IX, N.1, P.69-79, 2000.

Fonseca, M. R. M. Coleção Completamente química: físico-química - Ed. FTD, São Paulo 2001: $592 \mathrm{p}$.

Francisco Junior, W. E. . Uma abordagem problematizadora para o ensino de interações intermoleculares e conceitos afins. Química Nova na Escola, v. 29, p. 20-23, 2008.

Gil Perez, D. New trends in science education. International Journal of Science Education, v.18, n.8, p.889-901, 1996.

Goí, M. E. J. ; Santos, F. M. T.. Resolução de problemas e atividade experimentais no ensino de química. In: ENCONTRO NACIONAL DE ENSINO DE QUíMICA, 2008, Curitiba. XIV ENEQ. Curitiba, 2008.

Hofstein, A; Lunetta, V. N. The role of the laboratory in science teaching: Neglected aspects of research. Review of Educational Research, v.52, n.2, p. 201-217, 1982.

Insausti, M. J. Análises de los trabajos práticos de química general en un curso de universidad. Enseñanza de las Ciencias, v.15, n.1, p.123-130, 1997.

Macedo, L. Situação-Problema: Forma de Recurso de Avaliação, Desenvolvimento de Competências e Aprendizagem Escolar. In: Perrenoud, P. et al. As Competências para Ensinar no Século XXI: A FORMAÇÃO DOS PROFESSORES E O DESAFIO DA AVALIAÇÃO. Editora Artmed: Porto Alegre, 176p. 2002.

Machado, A. H. Aula de Química - discurso e conhecimento. 1. ed. Ijuí: Editora UNIJUÍ, v. 1. 200 p, 1999.

Martins, I. P.; Simões, M. O.; Simões, T. S., Lopes, J. M.; Costa, J. A., Ribeiro-Claro. EDUCAÇÃO EM QUÍMICA E ENSINO DE QUÍMICA - PERSPECTIVAS CURRICULARES-Parte II. Química. Boletim da Sociedade Portuguesa de Química, 95, pp. 42-45.

Meirieu, P. Aprender Sim, mas Como? 7. Ed. Porto Alegre: Editora Artmed, 1998.

Mortimer, E. F.; Machado, A. H. E Romanelli, L. I. A proposta Curricular de Química do Estado de Minas Gerais: fundamentos e pressupostos. Química Nova, v. 23, n. 2, p. 273-281, 2000.

Perrenoud, P. Construir as Competências desde a Escola. Porto Alegre: Artmed, 1999.

Pozo, J. I. Crespo, M. A. G. Aprender y Enseñar Ciencia. del conocimento Cotidiano al Conocimiento Científico. Madrid: Editora Morata, S.L. Fundada por Javier Morata, Editor, em 1920 c/ Mejia Lequerica. 1228004- Madri, p.011-330 1998. 
Santos, W. L. P.; Mól, G. S.; Matsunaga, R. T.; Dib, S. M. F.; Castro, E. N. F.; Silva, G. S.; Santos, S.; Farias, S. B., Química e Sociedade; volume único, ensino médio. 1. ed. São Paulo: Editora Nova Geração, 2005, 744p.

Schnetzler R. P. Concepções e Alertas sobre a formação continuada de professores de química.

Química Nova na Escola, n. 1, p. 27-31. 2004.

Silva, S. F.; Núñez, I. B. O Ensino por Problemas e Trabalho Experimental dos Estudantes Reflexões Teórico-Metodológicas. Química Nova, v. 25, n. 6B. p.1197-1203, 2002.

Zanon, D. A. P.; Freitas, D. A aula de ciências nas séries iniciais do ensino fundamental: ações que favorecem a sua aprendizagem. Ciência \& Cognição. V. 10, p. 93-103, 2007.

Zuliani, S. R. Q. A.; Ângelo, A. C. D. A utilização de metodologias alternativas: o método investigativo e a aprendizagem de química. In: Educação em Ciências da Pesquisa à Prática Docente. Ed. Escrituras: Autores Associados, p. 69-80, 2001.

Valéria Barboza Veríssimo. Professora da rede pública estadual de ensino de Pernambuco. Mestre em Ensino de Ciências pela Universidade Federal Rural de Pernambuco (UFRPE).

valeriaverissimo2002@gmail.com

Angela Fernandes Campos. Universidade Federal Rural de Pernambuco (UFRPE). Professora Associada 3 do Departamento de Química e membro permanente do Programa de Pós-Graduação em Ensino das Ciências. Doutora em Química pela Universidade Federal de Pernambuco. (UFPE). afernandescampos@gmail.com 